\title{
Prevalence of Underweight among Children Under-Five Years of Age in Rural Communities in Abuja
}

\author{
Article by Orji Ikechukwu Anthony \\ Disease Control Unit, Health Department, AMAC, Abuja, Nigeria \\ E-mail: drtony2013@gmail.com
}

\begin{abstract}
Background: The pre-MDGs prevalence of underweight among children under five years of age (MDGs goal 1, target 2, and indicator 4) for Nigeria was $35.1 \%$ by 1990. How successful was MDGs goal 1, target 2, indicator 4 in rural communities that benefited from MDGs activities in Nigeria? This is the cardinal research question that prompted this work. Objectives: To describe the post-MDGs underweight prevalence among children under-five years of age in the target population. To evaluate the progress made in reducing underweight among children under-five years of age with respect to achieving the MDGs goal 1, in the selected rural communities. Methods: This cross-sectional study used both primary and secondary data. The primary data was collected by direct weight measurement of the children under-five years of age from the selected communities, while secondary data were generated from the growth monitoring and delivery registers of the district PHC. Data were collated and analyzed using SPSS version 20.0. Result: The study recorded an underweight prevalence of $19.3 \%$ for children under-five years of age. Prevalence of underweight among the female subjects was $19.2 \%$ while their male counterpart was $19.5 \%$. Conclusion: The under-five underweight prevalence for these communities was $19.3 \%$ slightly better than the National 2014 prevalence of 19.5\%, however, still below the MDGs target of $17.75 \%$ at the end of 2015. More effort is therefore needed in the SDGs program to sustain the gain made via the MDGs activities and further improve the nutritional status of children under-five years of age in rural communities.
\end{abstract}

Keywords: Prevalence, underweight, under-five children, rural communities, SDGs, MDGs goall.

\section{Acronyms}

$\begin{array}{lll}\text { CSOs } & : & \text { Civil society Organizations } \\ \text { MNCHW } & : & \text { Maternal, Newborn and Child Health week } \\ \text { MDGs } & : & \text { Millennium Development Goals } \\ \text { MUAC } & : & \text { Mid Upper Arm Circumference } \\ \text { NGO } & : & \text { Non-Governmental Organization } \\ \text { PHC } & : & \text { Primary Health Center } \\ \text { SIPDs } & : & \text { Sub-National Immunization Plus Days } \\ \text { SDGs } & : & \text { Sustainable Development Goals } \\ \text { UN } & : & \text { United Nations } \\ \text { UNICEF } & : & \text { United Nations Children's Fund } \\ \text { USD } & : & \text { United States Dollars } \\ \text { WB } & : & \text { World Bank } \\ \text { WHO } & : & \text { World Health Organization }\end{array}$

\section{Introduction}

Millennium Development goals (MDGs) is the outcome of the millennium declaration signed by the head of governments of 189 countries in the year 2000 at the United Nations Millennium Summit with the central theme of eradicating poverty by the year 2015. MDGs consist of eight goals, with 18 targets that can be measured and explicit deadlines as well as 48 indicators to measure and track progress. The aim of 
DOI: $10.21522 / \mathrm{TIJPH} .2013 .05 .04 . A r t 003$

ISSN: $2520-3134$

this research revolves around assessing part of MDGs goal 1, which is: Eradicate extreme hunger and poverty.

The target 1 of this goal is to Halve, between 1990 and 2015, the proportion of people whose income is less than 1USD per day. The indicators for target 1 of goal 1 are as follows: 1. Proportion of the population below 1USD (1999 PPP) per day (MDG indicator 1). 2. Poverty gap ratio = incidence $\mathrm{x}$ depth of poverty (MDG indicator 2). 3. Share of the poorest quintile in national consumption (MDG indicator 3). Target 2 is to halve, between 1990 and 2015, the proportion of people who suffer from hunger with the following indicators: 1. Prevalence of underweight children under five years of age (MDG indicator 4). 2. Proportion of the population below minimum level of dietary energy consumption (MDG indicator 5).

This index research is focusing on MDG goal 1, target 2, and indicator 4, which is to assess the prevalence of underweight children less than five years of age in order to evaluate the nutritional status of the population. The research work will indirectly go a long way towards evaluating the outcome of various government intervention programs aimed at eradicating poverty and hunger within these beneficiary communities. It will also help in assessing the level of progress made with respect to achieving the MDG goal 1, Target 2, indicator 4. Furthermore, it will evaluate the gap if there is any. The findings will inform the recommendation to various stakeholders especially concerning achieving the ongoing SDGs $1 \& 2$, which is about eradicating extreme poverty and hunger.

\section{Objectives}

1. To describe the post-MDGs underweight prevalence among children under-five years of age in the target population.

2. To evaluate the progress made in reducing underweight among under-five children

\section{Literature review}

\section{Millennium development goals}

The millennium development goals (MDGs) which focus on health, development and eradication of poverty eradication by 2015 , is the outcome of the millennium declaration signed by the head of governments of 189 countries in the millennium summit held in New York in September 2000. The leaders made specific commitments in seven area: peace, security \& disarmament; development and poverty eradication; protecting our common environment; human rights, democracy and good governance; protecting the vulnerable; meeting the special needs of Africa; and strengthening the United Nations (Park, 2013). In these seven areas, the road map established goals and targets to be reached by 2015; the goals in the area of development and poverty eradication are what have culminated into the "millennium development goals".

The MDGs place health at the heart of development and represent commitments by governments throughout the world to do more to reduce poverty and hunger, and tackle ill-health, gender inequality, lack of education, access to clean water, and environmental degradation. Therefore, three of the eight goals are directly health related and all of other goals have important indirect effects on health, eight of the 18 targets are required to achieve these health related goals, and 18 of the 48 indicators of progress are health related (Park, 2013). Target 2 of MDG 1 is to halve, between 1990 and 2015, the proportion of people who suffer from hunger (United Nations, 2006). One of the indicators to track the progress in this direction is MDG indicator 4: Prevalence of underweight children under five years of age (United Nations, 2006).

\section{Under weight}

Underweight is defined as low weight for age. It can be due to stunting and or wasting. Stunting is low height for age which is a result of chronic under-nutrition and wasting is low weight for height which is a result of acute under-nutrition (Lucas \& Gilles, 2007). Under-nutrition is a major cause of mortality/morbidity worldwide; this has a global public health importance. In the severe form its presents as Marasmus or kwashiorkor (Collier et.al, 2003). According to Longmore et.al, undernutrition is a cause 
of slow recovery from illness, as well as cause of exaggerated complications experienced during some episodes of ill-health.

The best indicator for under-nutrition in children is poor growth and this can be detected through several methods such as; Comparing a child's weight or height to the median weight or height of a healthy reference population (reference value by WHO). This comparison is expressed as a percentage of the median or a $\mathrm{Z}$ score. $\mathrm{Z}$ score is the number of standard deviations from the median. This is the method employed in carrying out this research. Other methods includes; Monitoring weight gain using growth chart and measuring the mid upper arm circumference (MUAC) for children 6-59months old. According to Azubike and Nganginieme (1999), the growth chart is an important instrument in growth monitoring as a child survival strategy. The child's growth parameters including the immunization and other health status are recorded in the chart from the time of birth.

Table 1. The WHO standards of weight for age of boys and girls up to the age of 5years.

\begin{tabular}{|l|l|l|l|l|l|l|}
\hline AGE & \multicolumn{3}{|c|}{ BOYS } & \multicolumn{3}{c|}{ GIRLS } \\
\hline (Months) & -2 SD & Median & +2SD & -2 SD & Median & +2 SD \\
\hline 0 & 2.5 & 3.3 & 4.4 & 2.4 & 3.2 & 4.2 \\
\hline 4 & 5.6 & 7.0 & 8.7 & 5.0 & 6.4 & 8.2 \\
\hline 8 & 6.9 & 8.6 & 10.7 & 6.3 & 7.9 & 10.2 \\
\hline 12 & 7.7 & 9.6 & 12.0 & 7.0 & 8.9 & 11.5 \\
\hline 16 & 8.4 & 10.5 & 13.1 & 7.7 & 9.8 & 12.6 \\
\hline 20 & 9.1 & 11.3 & 14.2 & 8.2 & 10.4 & 13.5 \\
\hline 24 & 9.7 & 12.2 & 15.3 & 9.0 & 11.5 & 14.8 \\
\hline 28 & 10.2 & 12.9 & 16.3 & 9.7 & 12.3 & 16.0 \\
\hline 32 & 10.8 & 13.7 & 17.4 & 10.3 & 13.1 & 17.1 \\
\hline 36 & 11.3 & 14.3 & 18.3 & 10.8 & 13.9 & 18.1 \\
\hline 40 & 11.8 & 15.0 & 19.3 & 11.3 & 14.6 & 19.2 \\
\hline 44 & 12.2 & 15.7 & 20.2 & 11.8 & 15.3 & 20.4 \\
\hline 48 & 12.7 & 16.3 & 21.2 & 12.3 & 16.1 & 21.5 \\
\hline 52 & 13.2 & 17.0 & 22.2 & 12.8 & 16.8 & 22.6 \\
\hline 56 & 13.6 & 17.7 & 23.2 & 13.3 & 17.5 & 23.8 \\
\hline 60 & 14.1 & 18.3 & 24.2 & 13.7 & 18.2 & 24.9 \\
\hline A & 13 & & & & \\
\hline
\end{tabular}

Adapted from Parks, 2013, pp: 433

Using the WHO standard the normal weight is between the -2SD \& +2SD to the median reference. Thus under-weight is defined as less than -2SD to the median/ less than $80 \%$ of median/ less (-2) Z score. Further, the degree of under-weight can be classified as mild (less $80 \%$ to $70 \%$ of median), severe (less than $70 \%$ to $60 \%$ of median), severe (less than $60 \%$ of median).

\section{Child nutrition intervention programs in our environment}

The government has embarked on different nutrition intervention programs for children since the inception of millennium development goals. Notably among them is the Maternal, Newborn and Child health week (MNCHW) carried out twice a year with a 6month interval between successive programs. In this program, a total package of health intervention products is delivered to mothers and children less than five years of age. These include; vitamin A, de-worming tablets, zinc and oral rehydration salts, immunizations, nutrition assessment using MUAC, as well as health education to the mothers on adequate child/family nutrition, care of the newborn, hand hygiene, key household practices, family planning, tetanus toxoid immunization, antenatal care, etc. The assessment of the impact made by this program as regards the nutritional status of children under-five years of age is timely now that the MDGs is wound down and succeeded by SDGs which has its goal $1 \& 2$ addressing the issue of poverty and hunger. 
DOI: $10.21522 / \mathrm{TIJPH} .2013 .05 .04 . A r t 003$

ISSN: $2520-3134$

\section{Sustainable development goals (SDGs)}

The Sustainable Development Goals which is also known as the Global Goals, are a universal call to action to end poverty, protect the planet earth as well as to ensure that all people enjoy peace and prosperity (United Nations, 2015).

There are 17 Goals which build on the successes of the Millennium Development Goals, while including new areas such as climate change, economic inequality, innovation, sustainable consumption, peace and justice, among other priorities. The goals are as listed below: 1: No Poverty. 2: Zero Hunger. 3: Good Health and Well-being. 4: Quality Education. 5: Gender Equality. 6: Clean Water and Sanitation. 7: Affordable and Clean Energy. 8: Decent Work and Economic Growth. 9: Industry, Innovation and Infrastructure. 10: Reduced Inequality. 11: Sustainable Cities and Communities. 12: Responsible Consumption and Production. 13: Climate Action. 14: Life below Water. 15: Life on Land. 16: Peace and Justice Strong Institutions. 17: Partnerships to achieve the Goal (United Nations, 2015).The SDGs work in the spirit of partnership and pragmatism to make the right choices now to improve life, in a sustainable way, for future generations. The importance of eradicating extreme poverty and hunger cannot be overemphasized as shown by the transformation of this MDGs goal 1 into SDGs goals $1 \& 2$.

\section{Overview / trend of underweight in children less than five years}

According UNICEF-WHO-WB 2012 report, up to 101 million children under-five years of age were underweight amounting to $16 \%$ in 2011. This figure is far better than 159 million children found to be underweight in 1990. This gives about $36 \%$ decreases over eleven years period. However, this decrease in the number of children under five years of age who are underweight, overall, is not a sufficient progress towards eradicating under-nutrition. Liu et.al (2012) stated that in early childhood, adequate nutrition is very essential for proper growth and development and a well-nourished population is needed for economic growth and human development. Therefore, paying the right attention to nutrition is important for the progress and development of any society.

By definition, Prevalence of underweight children is the percentage of children under age 5 whose weight for age is more than two standard deviations below the median for the international reference population ages 0-59 months (Source: World Health Organization, 2016)

The prevalence of underweight in children under five years of age varies from countries, regions and continents of the world. Countries with low income per capita tend to have higher incidence of underweight than affluent/developed countries. For instance, in 2011, China and Mexico has underweight prevalence of $4 \%$ and 3\% respectively while Bangladesh and Chad, the same year recorded prevalence of $36 \%$ and $30 \%$ respectively (UNICEF-WHO-WB 2012).

Furthermore, there is also discrepancy between the prevalence of underweight in slum (higher prevalence) and non-slum (lower prevalence) area as recorded by an Indian survey. This supports the fact that higher prevalence of underweight is found among the poor than the rich (the slum area are populated by the poor). The 2005-2006 Indian survey of eight cities, the prevalence in slum area was in the range of $26-50 \%$ while in non-slum area range from $16 \%$ to $37 \%$ (NFHS India, 2005).

Underweight prevalence has been seen to drop among countries and regions that institutes a sustained nutritional program aimed at improving the nutritional status of the population. This is the case in Nigeria where the prevalence of underweight in children less than five years were seen to progressively drop from $35.5 \%$ in 1990 \& 1993, $29 \%$ in 2003, 26.7\% in 2007, 25.6\% in 2008, \& 24\% in 2011 (UNICEF, 2014), and 19.5\% in 2014 (World Bank, 2016)

\section{Summary}

The Nigerian 1990 underweight prevalence for children less than five years was 35.5\%(index mundi 2015) and it is expected to at least halve this figure by 2015 if we are to meet the MDG target, which is, bringing this figure down to $17.75 \%$ or less. By the end of 2014 , the prevalence has dropped to $19.5 \%$ (index mundi 2015), a significant progress towards achieving the MDG target by the end of 2015. In this study, therefore, an end of program assessment was carried out to evaluate the prevalence using this community and the district primary health center as a case study. 


\section{Methods}

This research work employed cross sectional study design because of limited scale and limited time duration. The target population was children under five years of age living in Kagini community and its environs. Kagini community with a population of over 15,500 inhabitants is located in kagini district, Gwagwa ward, Abuja Municipal Area council, Abuja, Nigeria. The populace is mainly of lowsocioeconomic status with farming and trading as the major occupation as well as a few public servants. It is populated by the indigenous Gbagy tribe and a mixture of other Nigerian ethnic groups. The study activity was set in Primary Health Center, Kagini, which is the public health facility that caters for kagini community and environs from where the members of the community were reached. The minimum sample size of 375 was calculated using the Survey System online sample size calculator, on the basis of the available population estimate of 15,500, at $95 \%$ confidence level and 5\% error margin. However, a superior sample of 564 participants was enrolled using a total sampling technique for secondary data and systematic random sampling for the primary data.

The study used a combination of primary and secondary data. The primary data collection was done by direct weight measurement of the children under-five years of age from the catchment communities under kagini district who attended the Primary Health center for a consecutive five day period between November $30^{\text {th }}$ through December $4^{\text {th }} 2015$ for the National Maternal, Newborn and Child Health Week (MNCHW) program that took place in the Federal capital territory. The first group of 282 children underfive years registered for the MNCHW was enrolled for the study to match the secondary data group.

Secondary data were generated from the Growth monitoring and delivery registers of Primary Health Centre, Kagini, by reviewing the weight and demographic data of the under-five children and newborns as recorded in the registers for the three month period covering September $1^{\text {st }}, 2015$ (twilight of the MDGs program) through November $29^{\text {th }} 2015$. The exclusion criteria were all children above five years (60 months) of age. Data extraction strategy involved the use of the growth monitoring register of this PHC where the weight, sex, and age as well as other data of the clients were recorded during their clinic visits and the delivery register where all newborns data including their birth weight were recorded. All the clients within the target age groups numbering 282 as recorded in these registers from September $1^{\text {st }}$ through November $29^{\text {th }} 2015$ were sampled for this study, thus, extracting the required variables which include their weight, sex and age from the relevant registers. SPSS version 20 was used to analyze the data and descriptive analysis test was performed to test the frequencies, percentages, cross-tabulation, Chi square and risk estimates.

\section{Ethical clearance}

Ethical approval was given by the ethical committee of the Health Department, Abuja Municipal Area Council, Federal Capital Territory, Nigeria. The confidentiality of patient's information was maintained throughout the research process.

\section{Results demographic analysis}

Table 2. Age distribution

\begin{tabular}{|l|l|l|}
\hline Age (months) & Frequency & Percent \\
\hline 0 & 102 & 18.1 \\
\hline 4 & 90 & 16.0 \\
\hline 8 & 82 & 14.5 \\
\hline 12 & 25 & 4.4 \\
\hline 16 & 21 & 3.7 \\
\hline 20 & 23 & 4.1 \\
\hline 24 & 24 & 4.3 \\
\hline 28 & 25 & 4.4 \\
\hline 32 & 18 & 3.2 \\
\hline 36 & 22 & 3.9 \\
\hline
\end{tabular}


DOI: $10.21522 / \mathrm{TIJPH} .2013 .05 .04 . A r t 003$

ISSN: $2520-3134$

\begin{tabular}{|l|l|l|}
\hline 40 & 11 & 2.0 \\
\hline 44 & 17 & 3.0 \\
\hline 48 & 24 & 4.3 \\
\hline 52 & 25 & 4.4 \\
\hline 56 & 25 & 4.4 \\
\hline 60 & 30 & 5.3 \\
\hline Total & 564 & 100.0 \\
\hline
\end{tabular}

Table 2, represents the age distribution of the participants which revealed that about $48.6 \%(274 / 564)$ were less than one year ( 0 - 11 months) of age, 12 - 23 months 12.2\% (69/564), $24-35$ months 11.9\% (67/564), 36 - 47 months 8.9\% (50/564), 48 - 60 months 18.4\% (104/564).

Table 3. Sex of respondents

\begin{tabular}{|l|l|l|l|l|l|}
\hline \multicolumn{2}{|c|}{} & Frequency & Percent & Valid Percent & $\begin{array}{l}\text { Cumulative } \\
\text { Percent }\end{array}$ \\
\hline \multirow{3}{*}{ Valid } & male & 277 & 49.1 & 49.1 & 49.1 \\
& female & 287 & 50.9 & 50.9 & 100.0 \\
& Total & 564 & 100.0 & 100.0 & \\
\hline
\end{tabular}

The distribution of the sex of the respondents is shown in Table 3, revealing that $49.1 \%$ were males while $50.9 \%$ were females representing a balanced ratio of approximately $1: 1$.

\section{Prevalence of underweight among under-five}

Table 4 shows the percentage of respondents who were underweight to be $19.3 \%$, while $80.7 \%$ were found to be of normal weight.

Table 4. Weight of respondents

\begin{tabular}{|l|l|l|l|l|}
\hline & Frequency & Percent & Valid Percent & Cumulative Percent \\
\hline Normal & 455 & 80.7 & 80.7 & 80.7 \\
Underweigh & 109 & 19.3 & 19.3 & 100.0 \\
$t$ & 564 & 100.0 & 100.0 & \\
Total & &
\end{tabular}

\section{Prevalence of underweight by gender}

Table 5. Cross-tabulation: sex of respondents * weight of respondents

\begin{tabular}{|l|l|l|l|l|}
\hline Male & & Normal weight & Underweight & Total \\
\hline & Count & 233 & 54 & 277 \\
\hline & $\%$ & $80.5 \%$ & $19.5 \%$ & $100 \%$ \\
\hline Female & Count & 232 & 55 & 287 \\
\hline & $\%$ & $80.8 \%$ & $19.2 \%$ & $100 \%$ \\
\hline Total & Count & 465 & 109 & 564 \\
\hline & $\%$ & $80.7 \%$ & $19.3 \%$ & $100 \%$ \\
\hline
\end{tabular}

Table 5 is a Cross-tabulation of the 'sex of respondents' versus 'weight of respondents' which shows that $19.5 \%$ of males against $19.2 \%$ of females were underweight, while, $80.5 \%$ of males against $80.8 \%$ of females were of normal weight

\section{Inferential statistics}

Table 6 shows chi square test yielding p-value of 0.927 which relates that there is no significant difference between the prevalence of underweight among male and female respondents 
Table 6. Chi square test

\begin{tabular}{|l|l|l|l|}
\hline & Value & Df & $\begin{array}{l}\text { Asymp. Sig. (2- } \\
\text { sided }\end{array}$ \\
\hline Pearson chi square & $\mathbf{0 . 0 1 0}$ & 1 & 0.927 \\
\hline
\end{tabular}

Table 7, revealed the study found that the risk of being underweight is approximately the same in both sexes among children under five years of age as the odds ratio is approximately 1 (1.017) with only a very slight and negligible tilt towards the male subjects

Table 7. Risk estimate

\begin{tabular}{|c|c|c|c|}
\hline \multirow[b]{3}{*}{$\begin{array}{l}\text { Odds Ratio For cohort } \\
\text { weight of respondents } \\
\text { (male/female) }= \\
\text { underweight } \\
\mathrm{N} \text { of Valid Cases }\end{array}$} & \multirow[t]{2}{*}{ Value } & \multicolumn{2}{|c|}{ 95\% Confidence Interval } \\
\hline & & Lower & Upper \\
\hline & $\begin{array}{l}1.017 \\
564\end{array}$ & .726 & 1.425 \\
\hline
\end{tabular}

Table 7 shows the risk estimate revealing that there is no higher risk for a particular sex being underweight as the odds ratio is approximately 1 (1.017)

\section{Sex of respondents * weight of respondents crosstabulation}

\section{Discussions}

By the end of 2015, the post-MDGs underweight prevalence among children under-five in the target communities was 19.3\% (Table 4). This statistic is slightly better than the Nigeria National 2014 prevalence of 19.5\%, (World Bank, 2016), however, still below the MGDs target of $17.75 \%$ at the end of 2015 (United Nations 2006 \& index mundi 2015). It is worthy to note that this reduction from prevalence of $35.5 \%$ in 1990 to a prevalence of $19.3 \%$ by the end of 2015 as recorded in this study among these communities is a great improvement. This progress in reducing the under-five prevalence reflects the result of the Government effort in improving the nutritional status of this vulnerable group through various intervention programs such as the bi-yearly MNCHW program, etc.,

Nevertheless, this progress cannot be compared with what obtained in Ghana, a similar sub-Saharan African nation which surpassed its own MDGs target by reducing her under-five underweight prevalence from 23\% in 1993 to $11 \%$ in 2014, as against her MDGs target of 11.5\% (Ghana MDGs 2015 Report).

Furthermore, the study showed that the prevalence of underweight among the female subjects was $19.2 \%$ while their male counterpart was $19.5 \%$ (Table 5). There is no significant gender difference in the prevalence of underweight ( $\mathrm{p}=0.927$, Table 6). This prevalence is similar to the 2014 disaggregated gender data from Ghana which reported that there was no significant difference of under-five underweight prevalence between the male and female gender (male $=10.6 \%$ and female $=11.6 \%$ ), however, while in Nigeria, male underweight prevalence was slightly higher than their female counterpart, the reverse was the case in Ghana (Ghana MDGs 2015 Report). Note that this is expected as there is no gender discrimination during implementation of nutritional intervention programs for this group.

\section{Conclusion}

The underweight prevalence among children under-five years of age for these communities was $19.3 \%$ slightly better than the Nigeria National 2014 prevalence of 19.5\%, however, still below the MGDs target of $17.75 \%$ at the end of 2015 . More effort is therefore needed in the SDGs program to sustain the gain made via the MDGs activities and further improve the nutritional status of children under-five years of age in rural communities. 
DOI: $10.21522 / \mathrm{TIJPH} .2013 .05 .04 . A r t 003$

ISSN: $2520-3134$

\section{Recommendation}

1. A critical review of the poverty alleviation/hunger eradication programs of the government under the MDGs should be done by the Government of Nigeria at the Federal, State and Local council level in conjunction with Implementing Partners at the three tiers of Government with a view to improve future programs under the SDGs, such that the goals $1 \& 2$ of the SDGs can be achieved.

2. Additionally, a closer study of the Ghana program with the aim of adopting best practice from her West African neighbor can benefit Nigeria Government in the area of hunger eradication, improving further the nutritional status of her populace and in achieving SDGs 2.

\section{Further research}

This index study used only one indicator to assess target 2 of Millennium Development Goal1, that is prevalence of underweight children under five years of age (MDG indicator 4), while this is a limitation, future study, can go further by including the second indicator ; Proportion of the population below minimum level of dietary energy consumption (MDG indicator 5). This will surely give a better and holistic assessment of this target 2 of MDGs; proportion of people who suffer from hunger.

\section{References}

[1]. Azubike J.C.,Nkanginieme K.E.O. (1999). Pediatrics and child heath in a tropical region. Owerri Nigeria, African educational services. pp: 132

[2]. Collier J., Longmore M., Scally P. (2003). Oxford handbook of clinical specialties, 6th Ed. New Delhi, Oxford university press. Pp: 186

[3]. Ghana Millennium Development Goals 2015 Report (2015). Accessed from www. UNDP_GH_2015\%20Ghana\%20MDGs\%20Report.pdf.

[4]. Index Mundi (2015). Nigeria - Malnutrition prevalence Accessed from

https://www.indexmundi.com/facts/nigeria/malnutrition-prevalence

[5]. Liu L, Johnson H.L, Cousens S, Perin J, Scott S, Lawn J.E, Rudan I, Campbell H, Cibulskis R, Li M, Mathers C, Black R.E,: For the Child Health Epidemiology Reference Group of WHO and UNICEF. Global, regional, and national causes of child mortality: an updated systematic analysis for 2010 with time trends since 2000. Lancet. 2012; 379:2151-61.

[6]. Longmore M., Wilkinson I., Torok E. (2001). Oxford handbook of clinical medicine, 5th Ed. New York, Oxford university press. Pp:454

[7]. Lucas A.O.,Gilles H.M. (2003) Short textbook of public health medicine for the tropics, 4th ed. London, Hodder Arnold. Pp: 262-263,

[8]. National Family Health Survey (NFHS-3) India 2005-06

[9]. Park K. (2013) Park's textbook of preventive and social medicine, 22nd Ed. Jabalpur India, Bhanot publishers Pp:11,

[10]. Survey System (2012). Sample size calculator. Accessed from https://www.surveysystem.com/sscalc.htm

[11]. UNDP (2015). Sustainable Development Goals. Accessed from

http://www.undp.org/content/undp/en/home/sustainable-development-goals.html

[12]. UNICEF Data: Monitoring the situation of women and children, 2014

[13]. United Nations (2015). Envision2030: 17 goals to transform the world for persons with disabilities. Accessed from https://www.un.org/development/desa/disabilities/envision2030.html

[14]. United Nations Children's Fund, World Health Organization, and the World Bank. UNICEF, WHO-World Bank Joint Child Malnutrition Estimates. (UNICEF, New York; WHO, Geneva; the World Bank, Washington DC; 2012).

[15]. United Nations Millennium projects; Goals, Targets, Indicators, 2006

[16]. World bank group (2015) ACCESSED FROM:

http://data.worldbank.org/indicator/SH.STA.MALN.ZS?locations=NG

[17]. World Health Organization (WHO 2016), Global Database on Child Growth and Malnutrition. Joint child malnutrition estimates - Levels and trends (2016 edition). Accessed from

http://www.who.int/entity/nutgrowthdb/jme_master_2016v2.xlsx?ua=1 